\title{
VASCULARIZATION OF THE OPTIC RADIATION AND THE VISUAL CORTEX*
}

\author{
BY \\ J. FRANÇOIS, A. NEETENS, AND J. M. COLLETTE \\ From the Ophthalmological Clinic of the University of Ghent and the Radiological Clinic of the \\ University of Liège, Belgium
}

THE vascularization of the optic radiation and the visual cortex has been studied in 27 normal hemispheres obtained from sixteen subjects aged 41 to 73 years. The following techniques were used:

(1) Injection of 33 per cent. Indian ink into the anterior choroidal, middle cerebral, and posterior cerebral artery, at a rate of $2 \mathrm{ml} . / \mathrm{min}$.; after dissection the degree of filling was determined according to blackness in frontal, transverse, and sagittal sections.

(2) Injection of Thorotrast with Paton blue at the rate of $2 \mathrm{ml} . / 3 \mathrm{~min}$.; the degree of filling was determined according to blueness, followed by microradiography.

(3) Injection of Thorotrast only, followed by microradiography.

\section{Anatomy of the Optic Radiation and of the Cortical Visual Centre}

(Fig. 1, opposite)

The anatomy of the regions studied was detailed according to a somewhat new concept, before the vascularization as such was examined.

\section{(A) Optic Radiation}

(1) The optic radiation originates from the carrefour (cross roads) where we find:

(a) The termination of the optic tract.

(b) The external geniculate body, the primary ganglionic optic centre, from which the Henschen tract arises to form, with fibres of the pulvinar, the optic radiation.

(c) The beginning of the optic radiation itself.

(d) The Wernicke field-a triangular formation pointing upwards, capping the external geniculate body (Foix and Masson, 1923; Schiff-Wertheimer, 1926).

The fibres of the optic radiation and those of the Wernicke field build up an intertwined pattern. The fibres of the optic radiation are directed outwards to the temporal horn of the lateral ventricle, crossing fibres which extend from the temporal region to the thalamus (Arnold's bundle). 


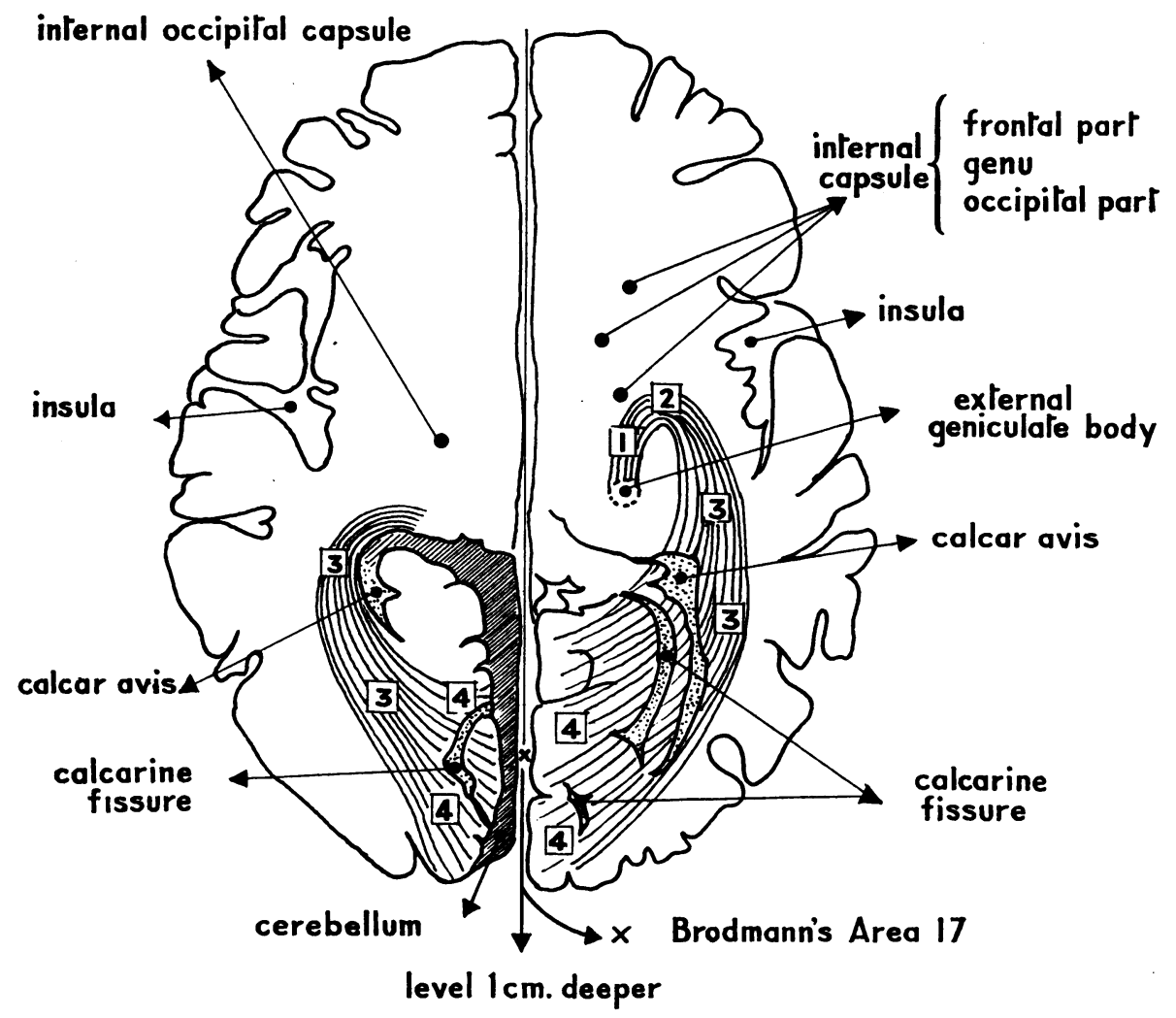

Fig. 1.-Anatomy of the optic radiation

(1) Optic radiation (carrefour)

(2) Temporal isthmus

(3) Ventricular part of the optic radiation

(4) Terminal part of the optic radiation

Once they have reached the level of the internal capsule, the fibres of the optic radiation turn in an oblique posterior direction, and describe a curve, the concavity of which embraces the external wall of the occipital prolongation of the lateral ventricle. This is known as the temporal isthmus.

(2) The temporal isthmus is $1 \mathrm{~cm}$. in width and $1.5 \mathrm{~cm}$. in length. In front it is delimited by the insula of Reyl and the external capsule, and behind by the lateral ventricle, the medial boundary being the thalamus and the internal capsule (Alexander, 1957). On the lateral side the fibres continue, and are indistinguishable from those of the temporal lobe.

(3) The temporal isthmus is followed by the ventricular part of the optic radiation. At this level the optic radiation is separated from the lateral ventricle by the tapetum - a thin white layer formed by fibres from the corpus callosum. On the external side the optic radiation fans out in the direction of the occipital lobe; it is delimited by the inferior longitudinal bundle which 
connects the occipital lobe with the temporal lobe. The optic radiation (projection bundle) thus extends between the tapetum (commissural bundle) and the inferior longitudinal bundle (association bundle).

(4) The terminal part of the optic radiation is divided into two bundles (Monbrun, 1924): a superior bundle, passing over the occipital horn of the lateral ventricle, and an inferior bundle, passing underneath this horn.

\section{(B) Cortical Visual Centre}

At the level of the cuneus we encounter the calcarine fissure, the superior lip of which receives the superior bundle of the optic radiation, while the inferior lip receives the inferior bundle.

This original anatomical division has been adopted because it corresponds with the various types of intratissular vascularization and the various parts depend on different nutritive sources.

\section{Macroscopic Vascularization of the Optic Radiation (Fig. 2)}

The vascularization of the optic radiation is dependent on three arteries: the anterior choroidal, middle cerebral, and posterior cerebral arteries, which run an irregular course and show frequent anomalies both in distribution and in division. This does not alter the fact that the degree of filling of the region examined after an injection into one of these arteries is constant.

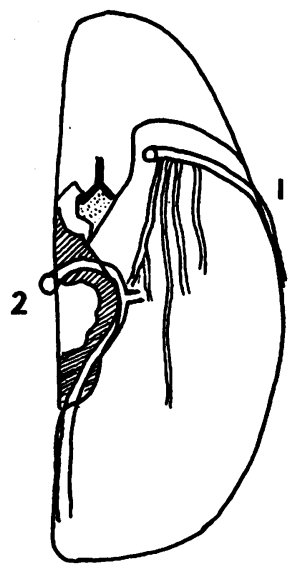

A

A: Inferior view of cerebral hemisphere.

$1=$ Middle cerebral artery (the anterior choroidal artery is considered as one of its tributaries).

$2=$ Posterior cerebral artery.

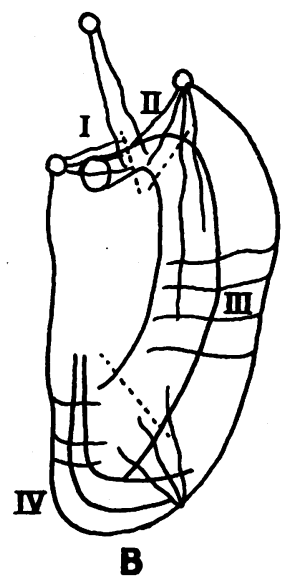

Fig. 2.-Vascularization of optic radiation

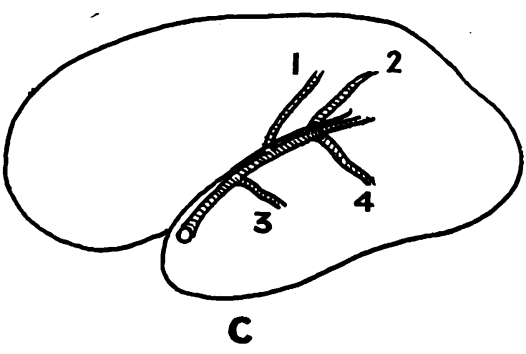

B: Section of cerebral hemisphere.

$\mathbf{I}=$ Anterior choroidal artery.

II = Middle cerebral artery.

III = Perforating branches at level of possible cortical anastomoses.

IV $=$ Posterior cerebral artery. 
(A) Anterior Choroidal Artery.-After leaving the internal carotid artery, or, in the majority of cases, the middle cerebral artery, it runs in an oblique postero-lateral direction, continues along the external side of the optic tract, and, arriving at the anterior end of the telediencephalic fissure of Bichat, passes into the choroid plexus of the lateral ventricle. Being strictly terminal, it branches off along its course into a number of collaterals, including direct or perforating branches, which, having participated in the irrigation of the optic tract, supply the anterior part of the optic radiation. An injection into the anterior choroidal artery, such as we have carried out five times, fills the retrolenticular part of the internal capsule, the carrefour region, and, to a lesser extent, the temporal isthmus. These regions are also irrigated by other arteries, which, however, do not anastomose with the anterior choroidal artery; the two networks, of different origin, are simply intermingled.

(B) Middle Cerebral Artery.-This shows a considerably higher degree of development than the anterior choroidal artery and has two important groups of collateral branches: the central perforating arteries, branching off in the vicinity of the circle of Willis, and the cortical arteries.

(1) Perforating Arteries.-These separate off at the beginning of the course of the middle cerebral artery, to disappear for the most part into the anterior perforated substance. Abbie (1933a, b; 1938) described among the perforating arteries a deep optic artery serving the optic radiation. This artery is not always single, however, but may be multiple. If the number of optic arteries is variable, the same holds true for the areas which they supply and for the depth to which they penetrate into the optic radiation; they may extend very far-even as far as the posterior third of the lateral ventricle.

(2) Arteries intended for the Cortico-Subcortical Region.-These penetrate much farther than the white matter immediately subjacent to the convolutions. They supply the optic radiation in the parietal lobe and many even extend as far as the ventricles. In order of importance these arteries are: the posterior parietal, ascending parietal, middle temporal, and posterior temporal (Fig. 2).

Although the middle cerebral artery extends very far back, almost as far as the occipital pole, it plays an unimportant role, if any, in the supply of this region.

Injection into the middle cerebral artery (seven hemispheres) completely filled the temporal isthmus and the ventricular part of the optic radiation; the carrefour region was filled much less, and the terminal part of the radiation and the occipital cortex were not filled at all.

Simultaneous injection of the anterior choroidal and middle cerebral artery (five hemispheres) was followed by maximal filling of the carrefour region, the temporal isthmus, and the ventricular part of the optic radiation.

(C) Posterior Cerebral Artery.-Along its course through the lateral mesencephalic groove, it is directed towards the infero-internal part of the 
hemisphere, and follows the posterior part of the internal border of the gyrus hippocampi. It reaches the calcarine fissure and then divides into two terminal branches: the parieto-occipital artery and the calcarine artery, which share the vascularization of the cuneus in an irregular way.

The posterior cerebral artery has two important groups of collateral branches: the central perforating arteries and the cortico-subcortical arteries.

(1) Central Perforating Arteries.-Passing the level of the external geniculate body, the posterior cerebral artery gives off a few branches (Hillemand's thalamogeniculate pedicle) which participate in the supply of the carrefour.

(2) Cortico-Subcortical Arteries.-These supply the cuneus, the visual region, and the inferior part of the occipital lobe. The calcarine artery is the most important and is distributed to the two lips of the calcarine fissure.

Injection into the posterior cerebral artery (seven hemispheres) was followed by maximal filling of the posterior and terminal parts of the ventricular portion of the optic radiation, and of the cortex.

Simultaneous injection of the medial cerebral artery and the posterior cerebral artery (three hemispheres) completely filled in addition the carrefour, the temporal isthmus, the ventricular and terminal parts of the optic radiation, and the cortex.

(D) Leptomeningeal Anastomoses.-These are of very great importance. Contrary to the opinion of Duret (1874) we agree with Heubner (1874), Testut (1895), and van der Eecken (1955) that anastomoses between the middle and the posterior cerebral artery are frequent. In no case did we inject one without filling the cortical regions supplied by the other. Within the part under discussion, anastomoses are found chiefly between the parietooccipital and the posterior temporal artery on the external temporal surface of the hemisphere. This fact makes it difficult to mark off the exact area supplied by each of these arteries.

It was impossible to obtain complete filling of the carrefour region and the temporal isthmus by injecting only into the anterior choroidal artery or only into the middle cerebral artery. Complete filling could be achieved, however, by simultaneous injection into both. This proves the existence not of an anastomosis but of a double vascularization as previously observed with reference to the optic tract; it also provides an explanation of the absence of hemianopia after isolated interruption of the anterior choroidal artery. The two vascular networks - that of the anterior choroidal artery and that of the middle cerebral artery-are not interconnected by arterioles or precapillaries; instead, the networks intermingle and overlap in a pseudoanastomotic network.

This double vascularization does not extend to include the ventricular and terminal parts of the optic radiation. There it is replaced by a network of 
cortico-subcortical perforating arteries which arise from largely anastomosed superficial arteries.

As far as the optic radiation is concerned, there are anatomical terminal arteries in depth and functional terminal arteries at the surface; the beginning of the optic radiation constitutes, from the vascular point of view, an overlapping zone receiving its supply from two or more arteries.

Malacic lesions occurring after the occlusion of a vessel are chiefly dependent, in our opinion, on the site of the occlusion and the rate at which it is formed.

Briefly, the vascularization of the carrefour and the temporal isthmus depends not only on the anterior choroidal artery, but also on the middle cerebral artery, and partly even on the posterior cerebral artery, which seldom intervenes by direct branches but often sends out indirect branches after having traversed the external geniculate body.

The ventricular part of the optic radiation is supplied by the middle cerebral artery, whereas the visual cortex and the subjacent optic radiation are entirely dependent on the posterior cerebral artery.

It should be remembered-as the fact is important-that there are wide leptomeningeal anastomoses between the middle and the posterior cerebral artery, and that the optic radiation shows overlapping in the deeper parts.

In summary, we have first a large central anastomotic circle (the arterial circle of Willis), then a second pseudo-anastomotic intracerebral circle (the overlapping zone in the nuclear regions), and finally a third superficial, peripheral circle formed by anastomoses between the middle and posterior cerebral artery (Fig. 3).

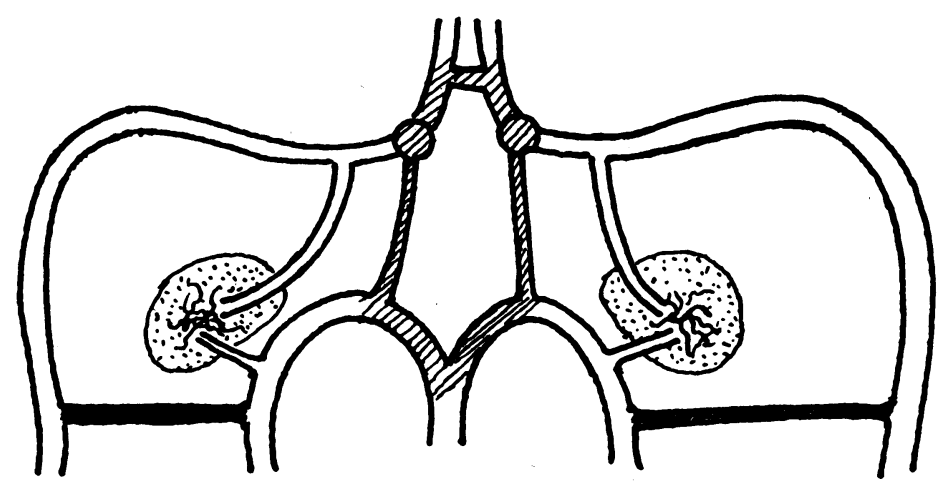

FIG. 3.-Anastomoses between the middle and posterior cerebral arteries.

A distinction may also be made between the central perforating arteries, which are collateral branches of the anterior choroidal and middle cerebral arteries (given off near the circle of Willis), and the peripheral corticosubcortical arteries. 
The central perforating collateral branches show the following characteristics:

(1) They are perpendicular to the course of the primary trunk;

(2) They are given off at the beginning of the course of the primary trunk;

(3) They remain isolated but are more or less numerous, often running parallel and close together, forming a true pedicle;

(4) They give off few collaterals before entering the region to be supplied;

(5) They are terminal (but this fact loses much of its importance in view of the double vascularization ensured by the collaterals of another artery);

(6) The vascular network formed by the central perforating branches always remains completely separate from the vascular network formed by the cortical arteries.

With regard to the peripheral cortico-subcortical arteries situated on the surface of the convolutions, their collaterals are seen to become even smaller; their division is not a dichotomy, but each new branch is perpendicular to the course of the collateral from which it originates, and in this way irregular rectangles and squares are formed. The branches which penetrate into the depths also remain perpendicular to the cortical surface. Deep within the fissures arterioles are often seen to penetrate the cerebral substance while spreading out in a fan-like pattern.

\section{Microscopic aND InTRATISSUlar VASCUlarization OF THE OPTIC RADIATION}

This characteristic vascularization reveals a corresponding myeloarchitecture and angio-architecture.

\section{(A) Arterioles and Precapillaries}

(1) Optic Radiation (fascicular part).-The course of the arterioles depends on the direction of the fibres. The following points may be noted:

(a) Arterioles are rare within the optic radiation proper, but remain outside on its borders. Some arterioles, on reaching the radiation, divide and abruptly change their course. Only precapillaries penetrate the radiation fanwise following the direction of the fibres.

(b) There are no anastomoses, not even between precapillaries.

At the level of the carrefour (Fig. 4, opposite), transverse sections show that the arterioles run parallel and that the precapillaries are crossed by others, in a vertical direction. Frontal sections show that they ramify, giving off branches which curve backwards in a regular pattern.

Near the temporal isthmus (Fig. 5, opposite) the arterioles outline the curve described by the fibres and, at the level of the isthmus itself, thick arterioles 


\section{VASCULARIZATION OF OPTIC RADIATION AND VISUAL CORTEX 401}

join the more or less tortuous courses of the fibres, thus demonstrating the complexity of the myelo-architecture. Farther back, more regular and elongated forms emerge, which typify the ventricular part of the optic radiation.

Fig. 4.-Carrefour region. Horizontal section. Thorotrast injection. Arteries and arterioles rare and parallel, running in two directions, oblique or perpendicular to each other. $\times 25$.
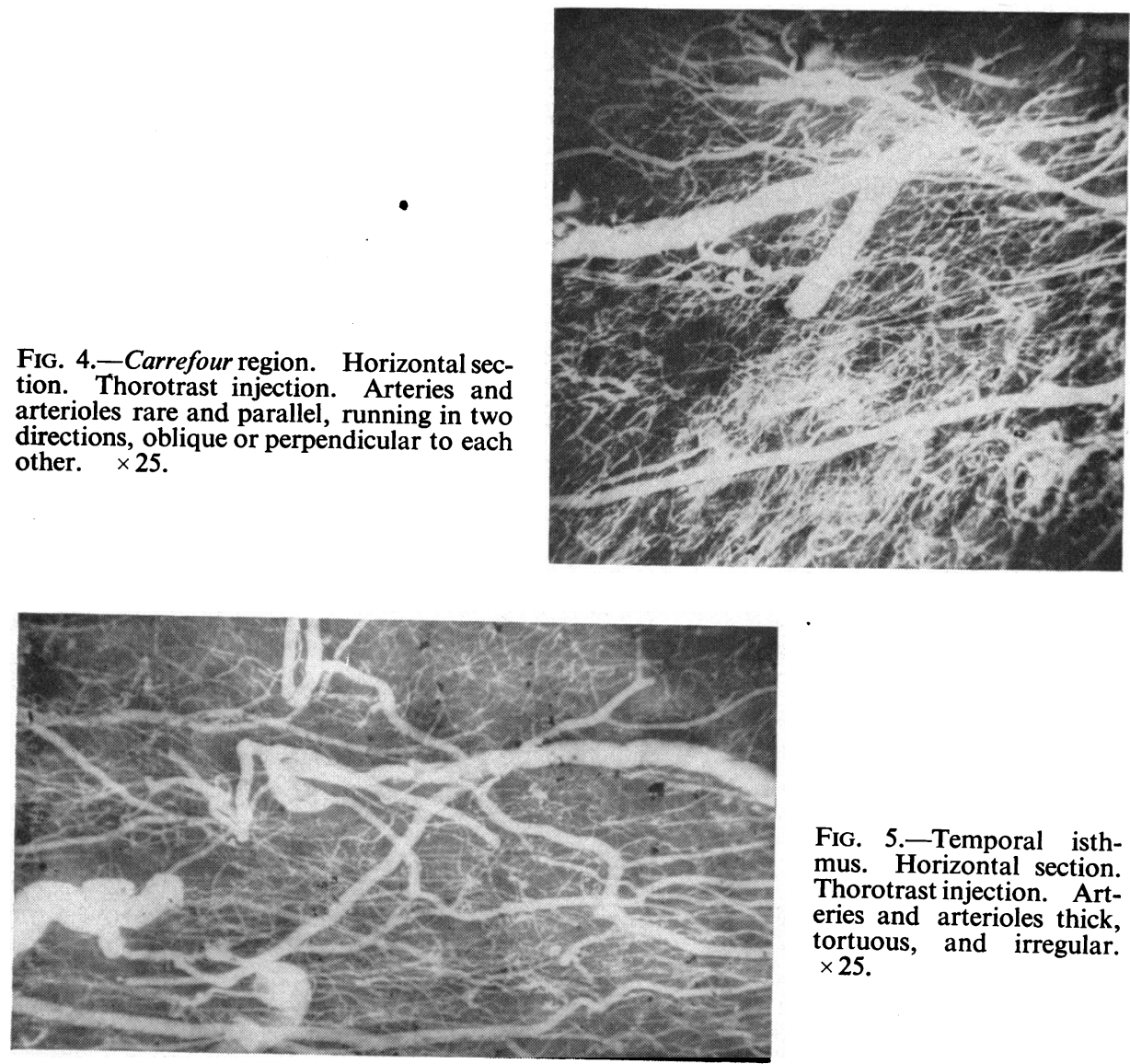

FIG. 5.-Temporal isthmus. Horizontal section. Thorotrast injection. Arteries and arterioles thick, tortuous, and irregular. $\times 25$.

At the level of the anterior zone of the optic radiation (Fig. 6), there is a characteristic fanning out of the arterioles.

Fig. 6.-Anterior ventricular part. Horizontal section. Thorotrast injection. Arterioles "parachuting" and sometimes curving backwards. Capillary system with polygonal meshwork, reminiscent of that of the optic tract. $\times 25$.

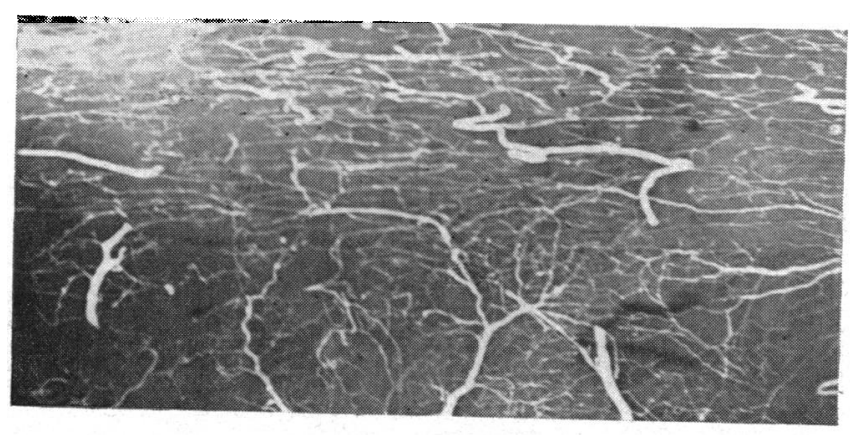


At the level of the median zone of the ventricular part of the optic radiation (Fig. 7), two types are seen: the slim, elongated arterioles which follow the direction of the fibres, and the thicker and more tortuous transverse arterioles.

Fig. 7.-Middle ventricular part. Parasagittal section. Thorotrast injection. Slim, elongated and thicker transverse arterioles. Capillaries rare. $\times 25$.

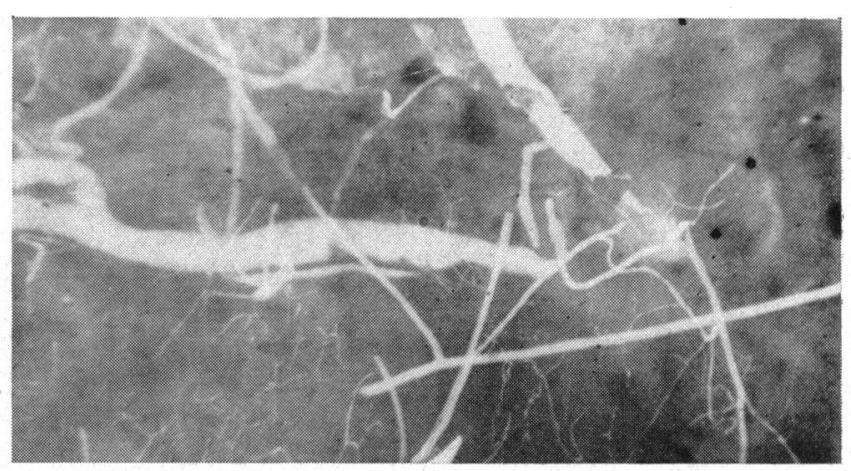

At the level of the posterior zone of the ventricular part of the optic radiation, the arterioles, all extending in an antero-posterior direction, begin to spread out fanwise.

At the conjunctions of two cortical areas, the fascicular vessels come together, and in places where a cortical area mushrooms out, the vessels spread out in tufts.

(2) Calcarine Cortex.-In the cortico-subcortical or cellulo-fascicular area (Fig. 8 and Fig. 9, opposite), two types of vessels are distinguishable:

(a) Short, medium, or long cellular arterioles, which form planes lying in layers parallel to the surface, with a straight or regularly meandering course.

The short vessels terminate at the superficial third of the cortex. The medium and long vessels continue to a greater depth, following a course perpendicular to

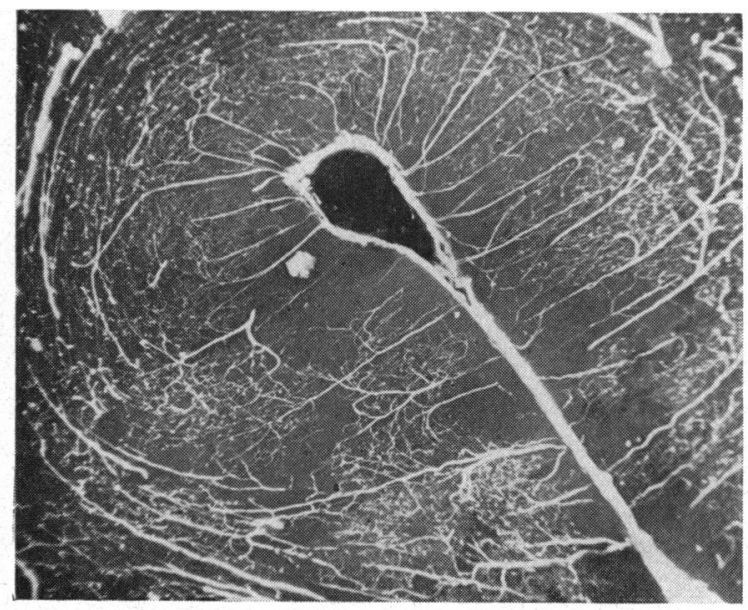

Fig. 8.-Visual cortex. Section perpendicular to surface. Thorotrast injection. Branching off of cellular and subcortical arteries. Fan pattern. $\times 10$. 
Fig. 9.-Visual cortex. Section perpendicular to surface. Thorotrast injection. Spiral branching off of fissure artery, with cellular and subcortical dependent arterioles. $\times 10$.

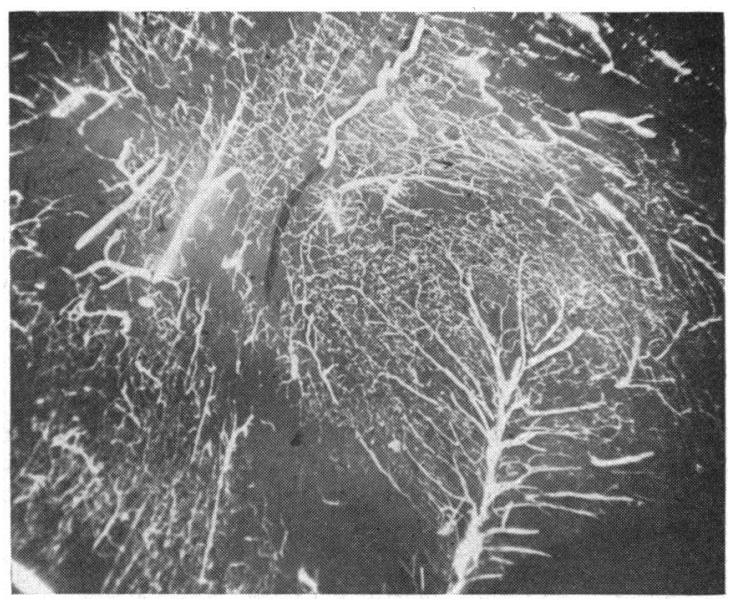

the cortical surface and forming collateral branches running parallel to it; sometimes these curve back again to the cortical zone.

(b) Long fascicular arterioles, which traverse the cortex and give off a few branches, then reach the white matter and follow the direction of the fibres. Generally, they converge like the spokes of a wheel towards the centrum ovale. In the depths of the fissures a spiral or fan pattern is seen.

\section{(B) Capillaries}

\section{(1) Optic Radiation.}

(a) Carrefour Region (Fig. 10).-Transverse sections show two intricate networks of capillaries placed perpendicularly, the first extending up and down, and the second extending from the postero-internal to the antero-external aspect.

In places, these capillaries join to form foci, and the question arises whether these are aberrant cells or nuclei of the external geniculate body.

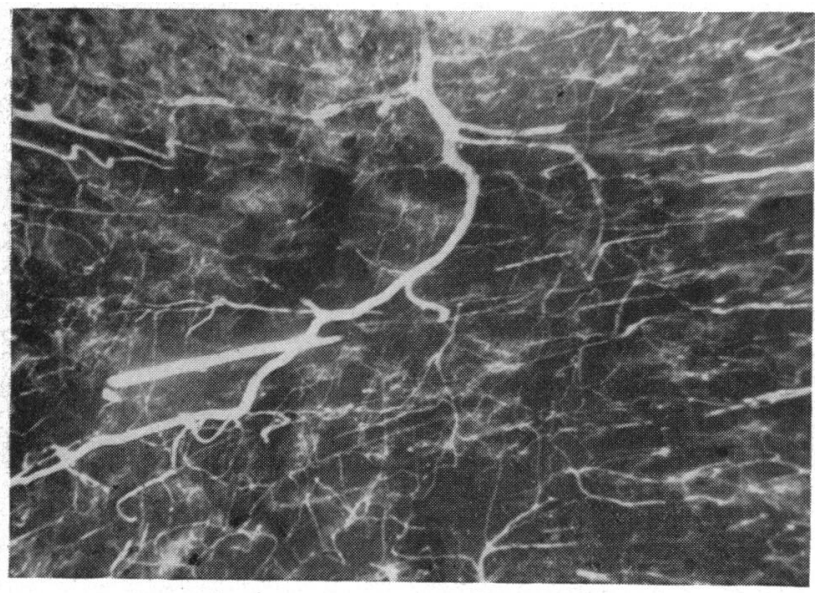

FiG. 10.-Carrefour region. Parasagittal section. Thorotrast injection. Two capillary directions perpendicular to each other. $\times 25$. 
(b) Temporal Isthmus (Fig. 11).-The capillary network forms very irregular meshes as a result of the anarchic capillary disposition.

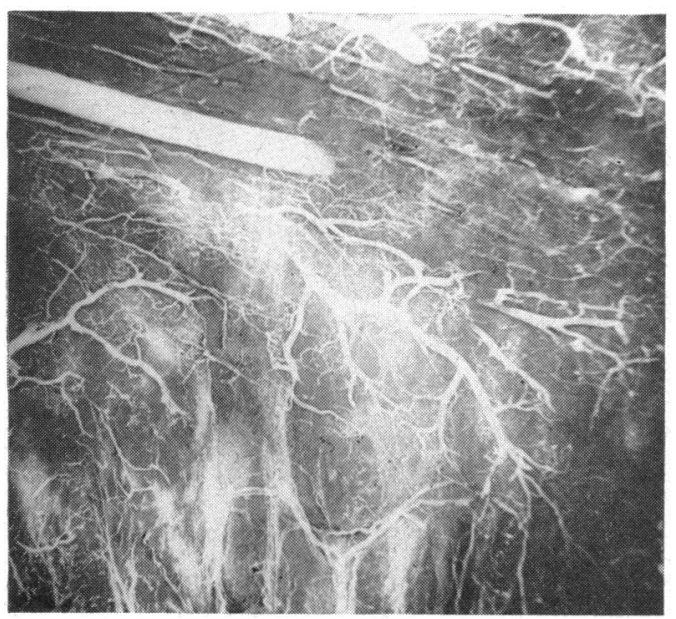

Fig. 11.-Temporal isthmus. Frontal section. Thorotrast injection. Very irregular and complex capillary system. $\times 10$.

(c) Ventricular Part of Optic Radiation.

(i) The anterior zone contains polygonal meshes, generally elongated, and more isolated longitudinal capillaries. The rounded or more irregular formations, from which arise other capillaries, are reminiscent of the picture seen at the level of the optic tract (Fig. 6).

(ii) The middle zone, in horizontal sections, shows long, thin capillaries, and pentagonal formations in transverse sections, reminiscent of those of the optic nerve (Fig. 12). Broad capillaries curving backwards are also sometimes seen.

Fig. 12.-Middle ventricular part. Transverse section. Thorotrast injection. Pentagonal capillary pattern, reminiscent of that of the optic nerve. $\times 25$.

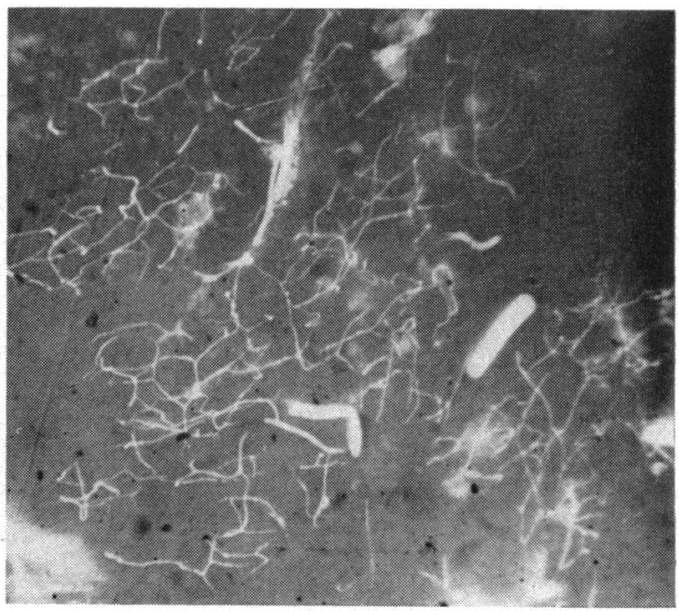

(iii) In the posterior zone the capillary network becomes clustered and more irregular, being composed of small meshes with no specific direction. 
(d) Visual Cortex (Figs 13 and 14, and Figs 15 and 16, overleaf).

(i) The superficial area, in sections parallel with the cerebral surface, shows a very fine, serrated network; it is sometimes lacking as injection is difficult, and it rapidly becomes obliterated.

(ii) The central area, which constitutes about 90 per cent. of the thickness, shows wider capillaries forming a looser network with larger meshes.

(iii) The area adjoining the white matter is similar, but shows finer capillaries and a denser network (Fig. 13).

FIG. 13.-Visual cortex. Section perpendicular to surface. Thorotrast injection. Summary view of different capillary layers of the cortex: the superficial very fine one (lacking), the middle larger one, and the finer and denser one.

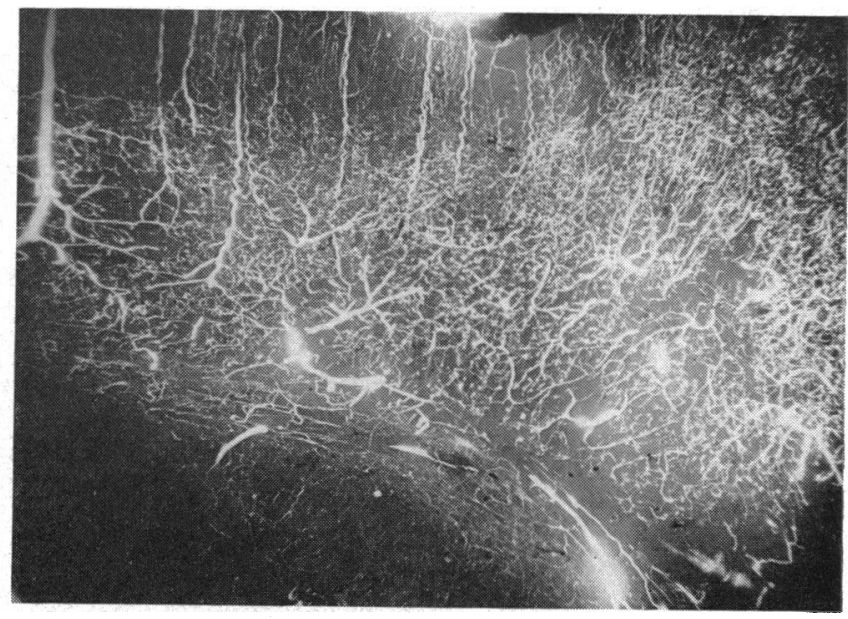

(iv) The immediately underlying white matter has wider capillaries which constitute a dense network following the zig-zag of the cortex, with meshes arranged in tiers like the tiles of a roof (Fig. 14).

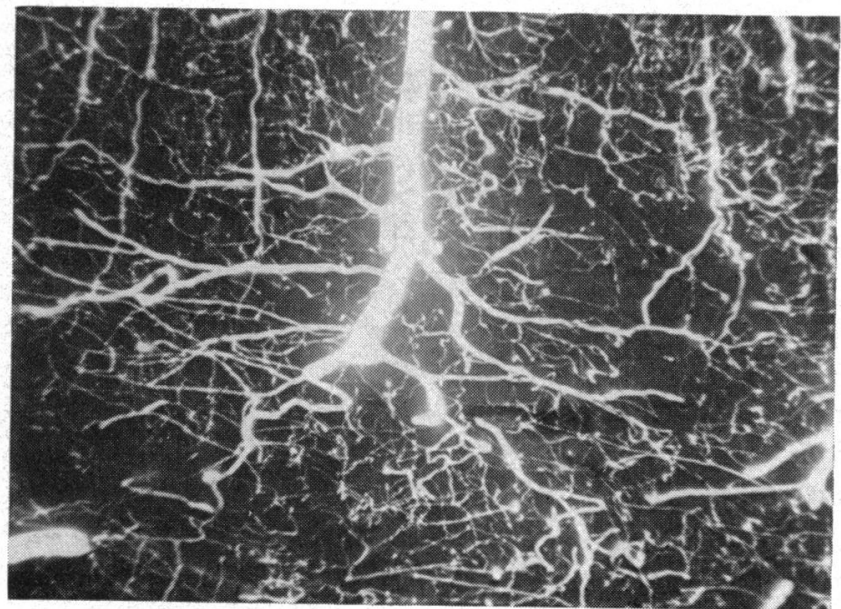

Fig. 14.-Visual cortex. Section perpendicular to surface. Thorotrast injection. Branching of subcortical arteriole, with rooftile capillary pattern.

(v) At the level of the white matter and of the terminal area of the optic radiation, the more or less parallel capillaries form a network with irregularly quadrangular and oblong meshes. 


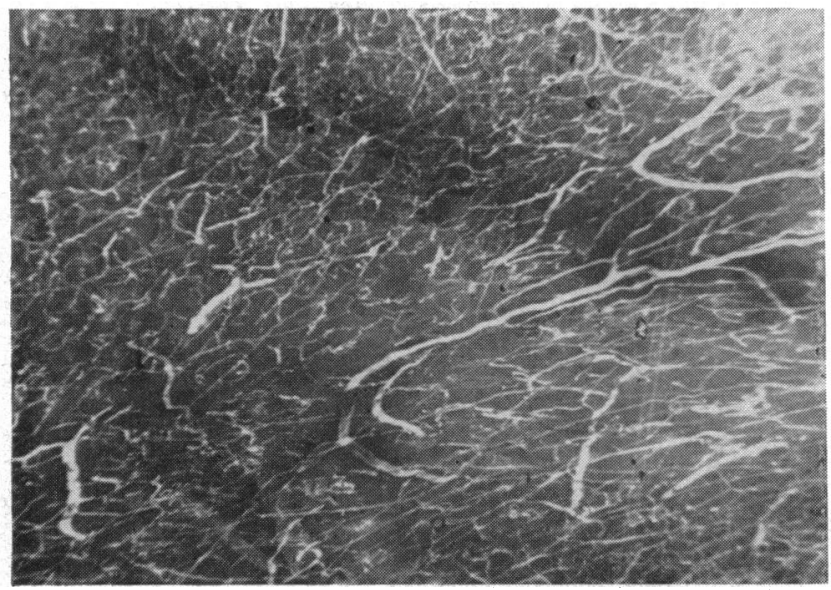

Fig. 15.-Visual cortex. Section oblique to surface. Thorotrast injection. Fascicular intercortical capillary system. $\times 25$.

Fig. 16.-Visual cortex. Section perpendicular to surface. Thorotrast injection. Part immediately adjacent to depth of calcarine fissure. The arterioles are lacking in the cellular layer, where they arrive not from the surface but from the fascicular depths. $\times 25$.

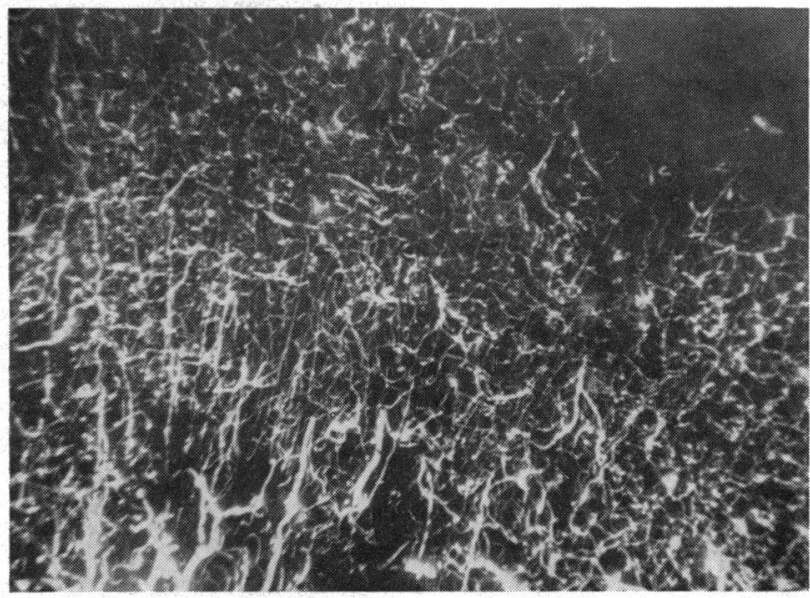

Between the capillary networks corresponding with the cortical and central arteries, zones often occur with less vascularization, as pointed out by Duret (1874).

(2) Calcarine Cortex.- It is a remarkable fact that the postero-central part of the cortical area of the calcarine fissure contains arterioles which become rarefied in the cortical layer, and disappear completely in a thin zone, the blood supply of which depends on arterioles arising from other deep regions by way of the fascicular zone; the capillary network in this zone is uniform and very dense. This fact may explain the sparing of the macula in certain vascular affections.

\section{Summary and Conclusions}

(1) From an anatomical point of view, the optic radiation is composed of four parts: the carrefour (cross roads), the temporal isthmus, the ventricular part, and the terminal part, which ends in the visual cortex.

(2) The vascularization of the carrefour and the temporal isthmus depends not only on the anterior choroidal artery but also on the middle cerebral 
artery and, to a lesser extent, on the posterior cerebral artery. The ventricular part of the optic radiation is primarily supplied by the middle cerebral artery, whereas the visual cortex and the subjacent optic radiation entirely depend on the posterior cerebral artery.

(3) There are large leptomeningeal anastomoses between the middle and posterior cerebral arteries. On the other hand the optic radiation shows an overlapping zone, which is supplied by two or more arteries (double vascularization).

(4) The vascular network formed by the central collaterals always remains completely independent of the vascular network arising from the cortical arteries.

(5) The intratissular vascularization of the optic radiation is characteristic throughout. There is correspondence between the myelo-architecture and the angio-architecture. There are no anastomoses between arterioles or precapillaries and the arterioles abruptly alter their course as soon as they reach the optic radiation and spread out in a fan pattern.

(6) The cortical region localized in the depth at the level of the calcarine fissure is deprived of arterioles and precapillaries over a narrow area.

(7) The carrefour region includes capillary formations with a typical cellular network radiating like the spokes of a wheel.

(8) Outside the central circle of Willis there is a superficial peripheral anastomotic circle and a pseudo-anastomotic (overlapping) circle of deep, central localization.

ABBIE, A. A. (1933a). Brain, 56, 233.

\section{REFERENCES}

(1933b). J. Anat. Lond., 67, 491.

(1938). Med. J. Aust., 2, 199.

AlEXANDER, H. B. (1957). Arch. Ophthal. (Chicago), 57, 65.

DURET, H. (1874). Arch. Physiol. norm. path., $2 \mathrm{e}$ série, 1, 60.

Forx, C., and Masson, A. (1923). Presse méd., 31, No. 32, p. 361.

HEUBNER, O. (1874). "Die luetische Erkrankung der Hirnarterien". Vogel, Leipzig.

Monbrun, A. (1924). Médecine (Paris), 5, 266.

SCHIFF-WERTHEIMER, S. (1926). "Les syndromes hémianopsiques dans le ramollissement cérébral". Thèse, Paris.

TestuT, J. L. (1895-1897). "Traité d'anatomie humaine, anatomie descriptive, histologie, développement", 3rd ed. Doin, Paris.

VAN DER EECKEN, A. (1955). "De Anastomosen tussen de leptomeningiale slagaders van het Encephalon". Thesis, Ghent. Ed. Erasmus, Ghent.

\section{ADDITIONAL BIBLIOGRAPHY}

BEEVOR, C. E. (1907). Brain, 30, 403.

De VRIESE, B. (1905). Arch. Biol. (Liège and Paris), 21, 357.

FAY, T. (1925). J. Amer. med. Ass., 84, 172.

HUGHES, B. (1954). "The Visual Fields", pp. 69-88. Blackwell, Oxford.

KERSHNER, C. M. (1943). "Blood Supply of the Visual Pathway". Meador, Boston.

KolISKo, A. (1891). "Uber die Beziehung der Arteria choroidea anterior zum hinteren Schenkel der inneren Kapsel des Gehirnes". Wien. klin. Wschr., 21. Hölder, Vienna.

Nielsen, J. M., and Friedman, A. P. (1942). Bull. Los Angeles neurol. Soc., 7, 1.

PFEIFFER, R. A. (1923). "Angio-architektonie der Grosshirninde". Berlin.

SHELlSHEAR, J. L. (1927). Brain, 50, 236.

Xuereb, G. P., Prichard, M. M. L., and Daniel, P. M. (1954). Quart. J. exp. Physiol., 39, 199. 